with the whole embodied for him in a wave-equation, might all too readily underrate. Thinking in terms of the general reader, I here felt uneasy. about the statement in the preface that the reader needs very little previous knowledge of physics; but it is only fair to say that anyone who had mastered the earlier chapters would have fortified himself well for the remainder, and that there is a well-chosen list of reference books of varying difficulty provided at the end.

To quote the preface again, there is much in the book that is addressed to both students and teachers of science. This is a very modest claim for a work which, while covering in outline all the main lines of progress, keeps before the reader always the interrelation between them. One cannot help feeling that the subject must often appear to students like a block of self-contained flats, each admirably designed. by an architect who has somehow omitted the stairs; the staircase here is a prominent and central feature of the work. Teachers will admire the craftsmanship of an excellent teacher, and will be able to refer to the book for chapter and verse when warning the impatient young that an apprenticeship in classical physics is essential for a full appreciation of modern ideas.

G. R. NOAKES

\section{ELECTRONS AND MATTER}

\section{Theory of Electrons}

By Prof. L. Rosenfeld. (Selected Topics in Modern Physics, 1.) Pp. xv+120. (Amsterdam: NorthHolland Publishing Co., 1951.) 7.50 f.; $15 s$.

T HE interpretation of the macroscopic electrical and magnetic properties of matter in terms of the behaviour of individual atoms and molecules plays so important a part in modern physics that it comes as a surprise to realize, on reading Prof. $L$. Rosenfeld's book, that up to now there has been no accessible text devoted exclusively to a discussion of the fundamental principles. Most students, unless they are prepared to seek out the relevant material from comprehensive treatises, must be content with only the vaguest conception of the elegant chain of argument by which, for example, Maxwell's equations and the phenomena of optical dispersion and scatter. ing are linked with the mechanies of simple atomic models. In a sense, the present book does nothing to alter the situation, since it shows that, like most fundamental theories, Lorentz's theory of electrons cannot be understood clearly without much careful thought. In fact, the subject is much more suitable for postgraduate than for undergraduate study. On the other hand, the whole book is so illuminated by Prof. Rosenfeld's enthusiasm that there is every encouragement for the serious student to master the niceties of the arguments.

The book varies greatly in complexity and depth of treatment. The first three chapters, occupying nearly half the book, set out the basic theorems concerning the microscopic field variables and their relation to macroscopic fields, and the dynamical theorems which lead to an understanding of, among other things, the gyromagnetic effects. The treatment here is generally very clear, except where occasionally, as on p. 16, over-conciseness leads to needless obscurity. The rest of the book deals with various topics - the magnetic properties of materials, dispersion theory, scattering of light and critical opalescence. The first is considered only in an elementary way (there is, intentionally, no attempt to present the detailed quantum theory of para. magnetism and ferromagnetism), and dispersion theory is treated at two levels, of which the second, the rigorous treatment, left me gasping for breath. The discussions of scattering and opalescence are, like the rigorous theory of dispersion, of much greater difficulty than the rest of the book and tend to make it top-heavy; but Prof. Rosenfeld in his preface disarms criticism by admitting that he could not resist the temptation to enlarge on so delightful a theme. In any event, it is useful to have these difficult matters clearly set out, and the resulting lack of unity does not in any way detract from the value of the book.

The publishers are to be congratulated on the appearance of their product and on the remarkable achievement of publication within four months of receipt of the manuscript.

A. B. Pippard

\section{STATISTICAL DECISION FUNCTIONS}

Statistical Decision Functions

By Prof. Abraham Wald. (Wiley Publications in Statistics.) Pp. ix +179. (New York: John Wiley and Sons, Inc. ; London : Chapman and Hall, Ltd., 1950.) 40s. net.

7 HE recent death of Prof. Abraham Wald in an aeroplane crash in India has deprived theoretical statistics of one of its ablest and most prolific researchers. This book is his last and most advanced work, and as a contribution to seientific methodology is likely to rank high for many years to come.

The book is best considered as part of a general movement which dates from the early days of the Second World War. The desire for economy in sampling led to the development of sequential analysis, in which a decision whether to accept or reject a batch is based on a sample of undetermined size selected one by one. Wald himself published a standard work on this subject in 1947. Later generalizations included the extension of the theory to the case of multiple decisions, where more than a simple dichotomy between acceptance and rejection is involved. This in turn, linking up with the theory of strategy in games and the testing of statistical hypotheses, has led to a general theory of decisions based on statistical data. There is a great deal of ground to be covered before this subject finds its feet. In the meantime, Wald's book marks a stage in one line of development to which he himself has contributed a great deal.

Wald, by training and inclination, was a synthesizer and a generalizer. He was at his best and his happiest when extending the scope of previous results and bringing apparently distinct lines of thought into one canon. Although his exposition is usually clear and never loose, this tendency towards generality makes his work rather abstract and difficult for a beginner to follow. Stochastic processes are encountered on p. 1, abstract spaces on p. 3, Borel fields on p. 6 and minimax strategies on p. 25 . In short, this is a very difficult book, and the ordinary reader will require a certain amount of preparation for it. Nevertheless, it represents some extremely stimulating lines of development in the theory of inference and experimentation which look as if they may have a permanent value. 